\title{
Surgical Aspects of Infective Endocarditis with Focus on the Aortic Root
}

\author{
Oscar Cuevas1, Vedran Savic1, Eduard Quintana2, Hector Rodriguez Cetina Biefer1, Francesco \\ Maisano1, Carlos A. Mestres1,2
}

1Zürich University Hospital, Department of Cardiovascular Surgery, Zürich, Switzerland

${ }^{2}$ Barcelona University Hospital, Department of Cardiovascular Surgery, Barcelona, Spain

\begin{abstract}
Infective endocarditis is an uncommon disease carrying a mortality between $10 \%$ and $25 \%$. The mitral and aortic valves are involved between $34-42 \%$ and $36-50 \%$ respectively. Early and aggressive treatment is mandatory, this impacts on early and long-term outcomes. A multi-disciplinary team approach is currently accepted as standard of practice. Approximately half of the patients require cardiac surgery as a part of the treatment. In case of extravalvular spread of infection, persistent sepsis, multiple embolic events despite appropriate antibiotic therapy, acute or worsening conduction abnormalities or heart failure, urgent surgery must be considered. When the infection involves the aortic root, a radical approach is preferred. As we expected, prosthetic valve endocarditis has worst outcomes, particularly related to the higher mortality in reoperations.
\end{abstract}

Keywords: Endocarditis, aortic, homograft

Cite this article as: Dzhinsov KR., Balabanski TL. Initial Experience Using AutoMark in Atrial Fibrillation Ablation. EJCM 2018;35:122-127. DOI: 10.32596/ejcm.00056

Presented in: Presented in part at the $14^{\text {th }}$ International Congress on Update in Cardiology and Cardiovascular Surgery, AHA days (Antalya, Turkey April 5-8, 2018).

\footnotetext{
Address for Correspondence: Carlos A. Mestres, Zürich University Hospital, Department of Cardiovascular Surgery, Zürich, Switzerland e-mail: carlos.mestres@usz.ch

Received: 23.11.2018 Accepted: 27.11.2018 Published: 30.11.2018

${ }^{\circ}$ Copyright 2018 by Heart and Health Foundation of Turkey (TÜSAV) / E Journal of Cardiovascular Medicine published by Galenos Publishing House.
} 


\section{Introduction}

Infective endocarditis (IE) was first described in 1885 by Osler who laid the foundations for its diagnosis: an existing lesion in one valve exposed to a infective injury ${ }^{(1)}$. Mortality was almost $100 \%{ }^{(2)}$ in the pre-antibiotic era. After antibiotics were introduced in clinical practice in 1928 by Sir Alexander Fleming, the mortality of the disease dramatically dropped ${ }^{(3)}$. However, despite new and improved antibiotics, mortality remains high, between 10 and $25 \%$ according to published series ${ }^{(4-11)}$.

IE is an uncommon disease that, as stated, carries significant morbidity and mortality and has a wide range of presentations ${ }^{(12)}$. Aortic valve IE frequency ranges between $36 \%$ to $50 \%{ }^{(13-15)}$ and IE of the mitral valve is observed between $34 \%$ to $42 \%{ }^{(14-17)}$ according to several studies.

Diagnosis is often difficult and challenging. Early diagnosis and aggressive management are fundamental for better outcomes ${ }^{(18-20)}$. Delayed diagnosis and treatment are mostly dictated by the complex nature of the disease. Surgery is currently contemplated as a part and not a failure of treatment as overall $50 \%$ of all IE patients will require an operation, which is also performed on urgent or emergency basis in a significant proportion of patients due to the preoperative condition ${ }^{(19,20)}$. A multidisciplinary approach is currently well accepted due to the complexity of this disease, thus resulting in the need for multiple specialists along the complex process of care ${ }^{(21,22)}$.

The concept of Endocarditis Team has been recently introduced and is now considered as a new standard of practice as the European Practice Guidelines have been instrumental in adopting this concept and form of practice $^{(23)}$ that has been preceded by some experiences in organization of dedicated valve and endocarditis teams ${ }^{(24-27)}$. Themain goal of Endocarditis Team is assisting in the decision-making process and aims at improving outcomes of medical and surgical therapy.

As a rule in IE, if the patient is in stable clinical condition, it is recommended to give antibiotic therapy for at least 1 or 2 weeks until the infection is clinically and microbiologically under control. Nevertheless, in the presence of progressive heart failure, uncontrolled infection or newly developed conduction abnormalities, early surgery must be considered and prioritized.

Timing for surgery continues to be a matter of controversy. Ideally, patients on antibiotic therapy should be operated when a Guideline-supported indication is present with at least 2 weeks of antibiotics, as the risk of the operation tends to be lower. This has been previously outlined by Lalani et al. ${ }^{(28)}$. In case of complications like abscesses, cardiac fistulas, false aneurysms, persistent large vegetations $(>10 \mathrm{~mm})$, fungal or multiresistant organism, persisting positive blood cultures and prosthetic valve endocarditis (PVE) caused for staphylococci or nonHACEK gram negative bacteria, urgent or emergency surgery must be considered ${ }^{(29,30)}$. Vegetation size should not be considered as an isolated indication for urgent or emergency surgery ${ }^{(13,23,31,32)}$. The indication for surgery is made in the presence of a major complication associated with a vegetation (i.e. septic embolism). The 2015 European Society of Cardiology Guidelines consider vegetations $>15 \mathrm{~mm}$ as class $\mathrm{IIb} \mathrm{C}$ and vegetations $>30 \mathrm{~mm}$ as class IIa B indication for urgent surgery. Thus, indications for surgery based on the size of vegetations have low level of evidence. Similar to the vegetation size, isolated embolic events are not an urgent or emergent indication for surgery. However, this also remains controversial. Urgent surgery should be considered in presence of a vegetation larger than $10 \mathrm{~mm}$ and one or multiple embolic episodes after adequate antibiotic treatment and in association with severe valve dysfunction (class IB indication).

\section{The Aortic Valve and Root}

Valve repair should initially be attempted. However, this is only possible in a reduced number of cases in the acute phase ${ }^{(16)}$. Valve replacement is mandatory most of the times. The election of the prostheses depends as usual, on the characteristic of the patient, anatomical presentation and expected outcomes. On our own experience, the type of replacement device does not present significant 
differences in overall survival over time (Figures 1, 2). Nevertheless, in the French-cohort presented by Delahaye et al., mechanical valves presented 1-year survival benefit compared to bioprostheses ${ }^{(33)}$.

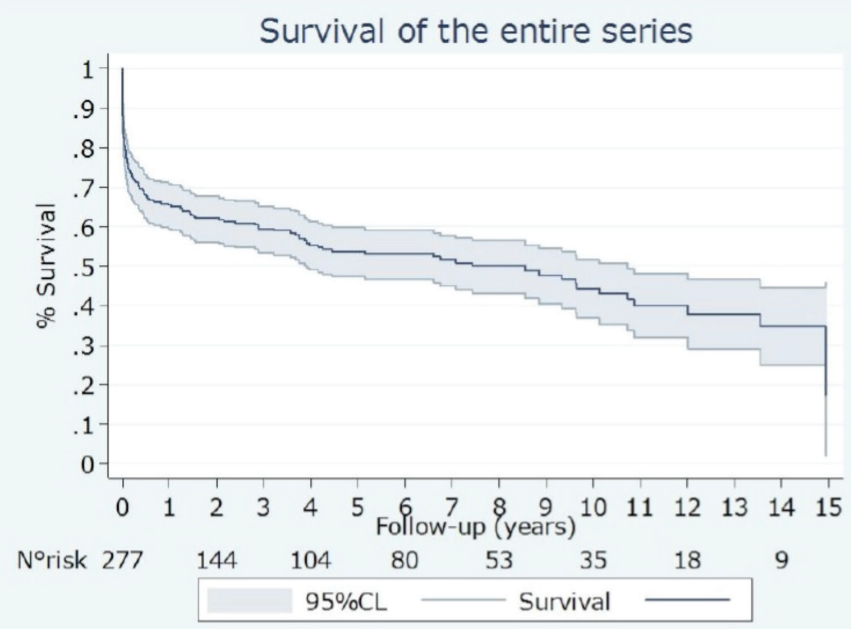

Figure 1. Overall survival of the Barcelona endocarditis group

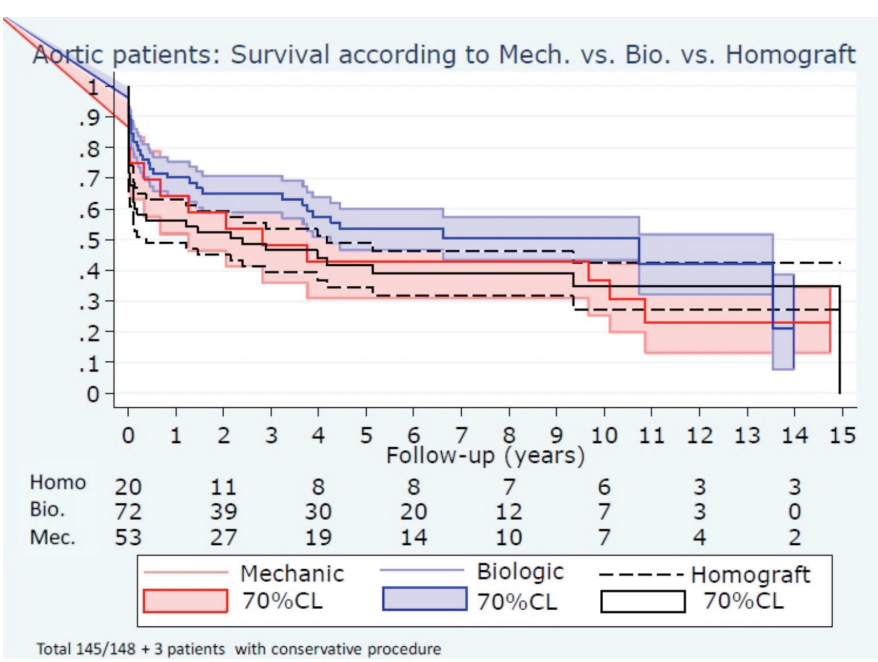

Figure 2. Survival comparison between aortic, mitral and double valve replacement

Aortic root infection is challenging, as there are several influencing factors. Some are common to all patients with IE regardless of the location of the infection such as preoperative clinical condition. Others have more impact on the anatomical region like extensive tissue destruction and extravalvular dissemination that may eventually lead to abscess and fistula formation. In relation to all these, there are intrinsic technical surgical difficulties and there are changes for recurrence of the IE. Local destructive effects lead to distortion and destruction of the valve, perforation of the leaflets, conduction abnormalities, functional valve obstruction and even purulent pericarditis.

The main objectives of surgery are saving the patient's life, restore function and restore anatomy. It is clear that major regurgitation in the presence of large vegetations and leaflet tissue destruction dictate replacement. It is necessary to excise all infected tissue apparent on gross examination followed by meticulous washing of all infected area.

Wallace et al. first described in 1965 the treatment of abscess of the aortic root by replacing the valve and the ascending aorta with the addition of coronary bypass grafting $^{(34)}$ due to regional destruction. Destruction of the root needs extensive reconstruction, which is often a technical challenge. In 1974 Danielson et al. described the reimplantation of the aortic valve in a distal position in the aorta with bypass of the coronary arteries, which was called "translocation of the aortic root"(35).

Different materials have been tested in clinical practice to replace the aortic root following the Bentall-De Bono technique for non-infected cases $^{(36)}$. This is a versatile procedure that can be performed using a mechanical or a tissue valve prosthesis ${ }^{(37)}$. Despite the available experience available on the Bentall-De Bono operation using mechanical or biological composite conduits in patients without IE, controversies in which material is better in IE remain. The phenomenon of biofilm formation, where adherent bacteria on vascular prostheses or felt is not uncommon and was found to be a factor in the pathogenesis of late graft infection ${ }^{(38,39)}$. This has been further explored and confirmed as some pathogens, specifically Staphylococcus aureus, have an increased tendency for biofilm development ${ }^{(40)}$. If synthetic prostheses are more prone to develop infection due to this is still controversial. Homograft human aortic valves have also been used for replacement of the aortic root for decades, part of the 
rationale for its use is its superior resistance to infection (Figure 3) ${ }^{(41)}$. Another less explored option in IE has been the auto-transplantation of the pulmonary valve into the aortic position, the Ross operation ${ }^{(42,43)}$ which some do recommend in IE. However, this type of operation, due to its complexity, is not common practice.

Extravalvular spread of infection can lead to regional

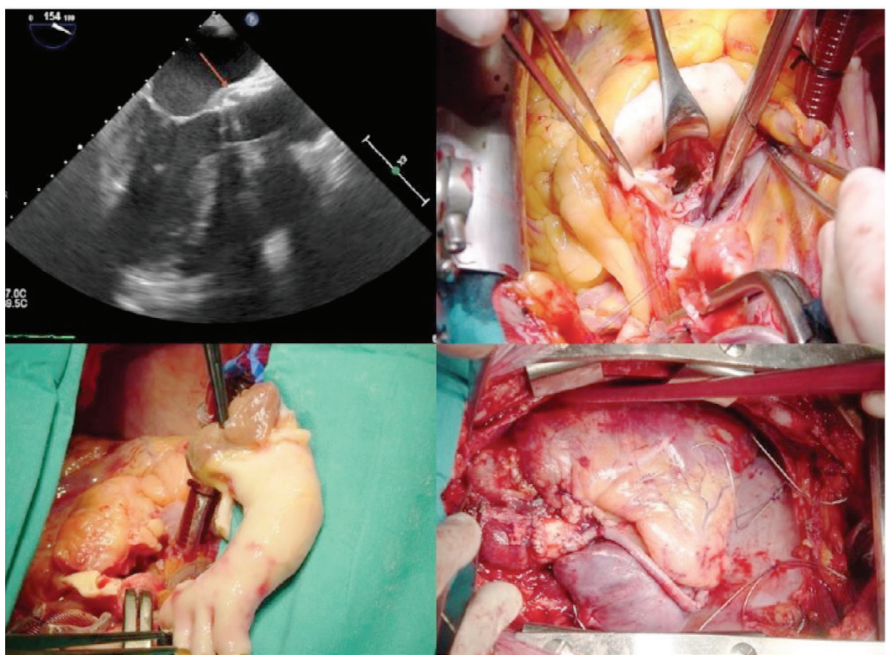

Figure 3. Homograft implantation in a patient with an abscess in aortic root (arrow)

destruction involving the fibrous skeleton of the heart and eventually affecting other valves such as the mitral valve. In such situations, a more aggressive approach is sometimes required. The reconstruction of the fibrous skeleton through the so-called "Hemi-Commando" or "Commando" operations represent a radical option that entails double valve replacement ${ }^{(44,45)}$.

\section{Results}

Despite advancements in prosthetic design and surgical technique, perioperative mortality in acute IE continues to be high. If the infection is restricted to the valve tissue, mortality ranges between 10 and $16 \%{ }^{(17)}$. Age over 65 years, preoperative inotropic requirement, uncontrolled sepsis, left side endocarditis and cerebral embolization have been found to be significantly associated with increased mortality ${ }^{(14)}$. Yankah et al. reported a survival rate of $70.4 \pm 3.6 \%$ in a 17 -year follow-up which stabilizes during the follow-up after the fourth year ${ }^{(46)}$. Same authors also reported a freedom from residual/recurrent infection and paravalvular leaks of $91.6 \pm 2.4 \%$ up to 15 years when homografts were used.

Musci et al. in their 20-year experience showed a significant difference in patient survival when surgery was performed for native valve or PVE, $47.3 \pm 5.6 \%$ and $35.0 \pm 5.4 \%$, respectively ${ }^{(41)}$.

In 2012 Leontyev et al. reported a series of 172 patients operated for aortic root abscess, with a $100 \%$ follow-up ${ }^{(47)}$. Overall thirty-day mortality was $25 \%$ and the independent predictors of mortality were sepsis, concomitant mitral an aortic endocarditis, renal insufficiency, concomitant coronary artery bypass grafting and PVE. The survival at 1 and 5 years was $55 \%$ and $50 \%$, respectively.

Reoperations are always challenging procedures in IE. Shrestha et al. have underscored this in 2010 in a series of 26 root reoperations ${ }^{(48)}$. The mean cardiopulmonary bypass was $219 \mathrm{~min}$ (range 101-398 $\mathrm{min}$ ), the mean aortic cross-clamp 142 min (range 89-253 $\mathrm{min}$ ), the mean ICU stay was 8 days (range 1-45 days) and the mean hospital stay 20 days (range 3-64 days). Reoperation for bleeding was required in $14 \%$. Early mortality was $8 \%$ and $12 \%$ required pacemaker implantation. These data highlight the complexity reoperations in IE.

Jassar et al. attempted to elucidate the importance of graft material in aortic root replacement for $\mathrm{IE}^{(49)}$. They retrospectively analyzed 134 patients with IE undergoing aortic root replacement and they were not able to observe significant differences in survival between mechanical or biological composite or homograft replacement. In the abovementioned study, the 5-year survival rate was $58 \pm 9 \%$ for mechanical composite, $62 \pm 7 \%$ for biological composite and $58 \pm 9 \%$ for homografts $(\mathrm{p}=0.48)$. Whether a given material offers survival benefit still remains controversy. The lack of well-designed and powered controlled studies does not allow drafting solid conclusions within this regard. In our own experience, there were no statistical significant differences in the survival of 
aortic patients at 15 years with mechanical, biological or homograft replacement devices.

\section{Conclusion}

IE is an uncommon disease still carrying high morbidity and mortality. Over time, it seems clear that referral of the patient to a tertiary-care institution with a dedicated Endocarditis Team is of utmost importance for better survival. As it is almost universally accepted today, the Endocarditis Team must be contemplated as a standard of practice, as it helps in providing an appropriate highquality care for this complex patients; therefore, this practice is contemplated in current Guidelines.

Valve replacement is the "gold standard" of care for patients with IE in the aortic position, with slim chances for favorable valve repair. More complicated extravalvular spread of infection requires aggressive root replacement. Homograft replacement has classically been considered, aiming full root reconstruction and reducing the eventual reinfection rate during the follow-up. However, it is not clear from the available data, that this is a superior option compared to biological or mechanical composites.

Itis clearthat IErequires an earlydiagnosis. Furthermore, the combination of intravenous antibiotic therapy for at least two weeks and surgical treatment renders the best results in patients with a surgical indication in terms of outcomes and perioperative complications.

\section{References}

1. Osler W. The Gulstonian Lectures, on Malignant Endocarditis. Br Med J 1885; $1: 467-70$

2. White PD, Mathews M, Evans E. Notes on the treatment of subacute bacterial endocarditis encountered in 88 cases at the massachusetts general hospital during the six year period 1939 to 1944 (inclusive). Ann Intern Med 1945;22:61-74.

3. Baker KS, Burnett E, McGregor H, et al. The Murray collection of preantibiotic era Enterobacteriacae: a unique research resource. Genome Med 2015;7:97.

4. Van der Meer JT, Thompson J, Valkenburg HA, Michel MF. Epidemiology of Bacterial Endocarditis in the Netherlands: II. Antecedent Procedures and Use of Prophylaxis. Arch Intern Med 1992;152:1869-73.

5. Watanakunakorn $\mathrm{C}$, Burkert $\mathrm{T}$. Infective endocarditis at a large community teaching hospital, 1980-1990. A review of 210 episodes. Medicine (Baltimore) 1993;72:90- 102
6. Hogevik H, Olaison L, Andersson R, Lindberg J, Alestig K. Epidemiologic Aspects of Infective Endocarditis in an Urban Population: A 5-year Prospective Study. Medicine (Baltimore) 1995;74:324-39.

7. Mansur AJ, Grinberg M, Cardoso RH, da Luz PL, Bellotti G, Pileggi F. Determinants of Prognosis in 300 Episodes of Infective Endocarditis. Thorac Cardiovasc Surg 1996;44:2-10.

8. Hoen B, Alla F, Selton-Suty C, et al. Changing Profile of Infective Endocarditis: Results of a 1-Year Survey in France. JAMA 2002;288:75-81.

9. Ferreiros E, Nacinovich F, Casabé JH, et al. Epidemiologic, clinical, and microbiologic profile of infective endocarditis in Argentina: A national survey. The Endocarditis Infecciosa en la República Argentina-2 (EIRA-2) Study. Am Heart J 2006;151:545-52.

10. Cahill TJ, Prendergast BD. Infective endocarditis. Lancet 2016;387:88293.

11. Bustamante-Munguira J, Mestres CA, Alvarez P, et al. Surgery for acute infective endocarditis: epidemiological data from a Spanish nationwide hospital-based registry. Interact Cardiovasc Thorac Surg 2018;27:498-504.

12. Kaura A, Dworakowska D, Dworakowski R. Infective endocarditis Cinderella in cardiology. Kardiol Pol 2017;75:965-74.

13. Baddour LM, Wilson WR, Bayer AS, et al. Infective endocarditis in adults: diagnosis, antimicrobial therapy, and management of complications: a scientific statement for healthcare professionals from the American Heart Association. Circulation 2015;132:1435-86.

14. Dunne B, Marr T, Kim D, et al. Infective Endocarditis. Heart Lung Circ 2014;23:628-35

15. Ilhão Moreira R, Coutinho Cruz M, Moura Branco L, et al. Infective endocarditis: Surgical management and prognostic predictors. Rev Port Cardiol 2018;37:387-94

16. Poesen K, Pottel H, Colaert J, De Niel C. Epidemiology of infective endocarditis in a large Belgian non-referral hospital. Acta Clin Belg 2014;69:183-90

17. Wang A, Gaca JG, Chu VH. Management Considerations in Infective Endocarditis: A Review. JAMA 2018;320:72-83.

18. Fukuchi T, Iwata K, Ohji G. Failure of early diagnosis of infective endocarditis in Japan--a retrospective descriptive analysis. Medicine (Baltimore) 2014;93:237.

19. Thuny F, Grisoli D, Collart F, Habib G, Raoult D. Management of infective endocarditis: challenges and perspectives. Lancet 2012;379:965-75.

20. Habib G. Management of infective endocarditis. Heart 2006;92:124-30.

21. Wilson W, Taubert KA, Gewitz M, et al. Prevention of infective endocarditis: guidelines from the American Heart Association: a guideline from the American Heart Association Rheumatic Fever, Endocarditis, and Kawasaki Disease Committee, Council on Cardiovascular Disease in the Young, and the Council on Clinical Cardiology, Council on Cardiovascular Surgery and Anesthesia, and the Quality of Care and Outcomes Research Interdisciplinary Working Group. Circulation 2007;116:1736-54

22. Meier S, Hasse B, Haller C. CME: Infectious endocarditis. Praxis 2016;105:739-46.

23. Habib G, Lancellotti P, Antunes MJ, et al. 2015 ESC Guidelines for the management of infective endocarditisThe Task Force for the Management 
of Infective Endocarditis of the European Society of Cardiology (ESC) Endorsed by: European Association for Cardio-Thoracic Surgery (EACTS), the European Association of Nuclear Medicine (EANM). Eur Heart J 2015;36:3075-128.

24. Chirillo F, Scotton P, Rocco F, et al. Impact of a Multidisciplinary Management Strategy on the Outcome of Patients With Native Valve Infective Endocarditis. Am J Cardiol 2013;112:1171-6.

25. Chambers J, Ray S, Prendergast B, et al. Standards for heart valve surgery in a "Heart Valve Centre of Excellence." Open Heart 2015;2:e000216.

26. Mestres CA, Paré JC, Miró JM; Working Group on Infective Endocarditis of the Hospital Clínic de Barcelona. Organization and Functioning of a Multidisciplinary Team for the Diagnosis and Treatment of Infective Endocarditis: A 30-year Perspective (1985-2014). Rev Esp Cardiol 2015;68:363-8.

27. Chambers J, Sandoe J, Ray S, et al. The infective endocarditis team: recommendations from an international working group. Heart 2014;100:524-7.

28. Lalani T, Cabell CH, Benjamin DK, et al. Analysis of the Impact of Early Surgery on In-hospital Mortality of Native Valve Endocarditis: Use of Propensity Score and Instrumental Variable Methods to Adjust for Treatment Selection Bias. Circulation 2010;121:1005-13.

29. Anantha Narayanan M, Mahfood Haddad T, et al. Early versus late surgical intervention or medical management for infective endocarditis: a systematic review and meta-analysis. Heart 2016;102:950-7.

30. Kang DH, Kim YJ, Kim SH, et al. Early surgery versus conventional treatment for infective endocarditis. N Engl J Med 2012;366:2466-73.

31. Okonta KE, Adamu YB. What size of vegetation is an indication for surgery in endocarditis? Interact Cardiovase Thorac Surg 2012;15:1052-6.

32. Kang DH. Timing of surgery in infective endocarditis. Heart 2015;101:178691.

33. Delahaye F, Chu VH, Altclas J, et al. One-year outcome following biological or mechanical valve replacement for infective endocarditis. Int $\mathrm{J}$ Cardiol 2015;178:117-23.

34. Wallace AG, Young WG Jr, Osterhout S. Treatment of acute bacterial endocarditis by valve excision and replacement. Circulation 1965;31:4503 .

35. Danielson GK, Titus JL, DuShane JW. Successful treatment of aortic valve endocarditis and aortic root abscesses by insertion of prosthetic valve in ascending aorta and placement of bypass grafts to coronary arteries. J Thorac Cardiovasc Surg 1974;67:443-9.

36. Bentall H, De Bono A. A technique for complete replacement of the ascending aorta. Thorax 1968;23:338-9.

37. Di Eusanio M, Murana G, Cefarelli M, Mazzola A, Di Bartolomeo R. The Bentall procedure with a biological valved conduit: substitute options and techniques. Multimed Man Cardiothorac Surg 2014:2014.
38. Schmitt DD, Bandyk DF, Pequet AJ, Towne JB. Bacterial adherence to vascular prostheses. A determinant of graft infectivity. J Vasc Surg 1986;3:732-40.

39. Bergamini TM, Corpus RA Jr, Brittian KR, Peyton JC, Cheadle WG. The natural history of bacterial biofilm graft infection. J Surg Res 1994;56:3936.

40. Van de Vyver H, Bovenkamp PR, Hoerr V, et al. A Novel Mouse Model of Staphylococcus aureus Vascular Graft Infection: Noninvasive Imaging of Biofilm Development in Vivo. Am J Pathol 2017;187:268-79.

41. Musci M, Weng Y, Hübler M, et al. Homograft aortic root replacement in native or prosthetic active infective endocarditis: Twenty-year single-center experience. J Thorac Cardiovasc Surg 2010;139:665-73.

42. Ratschiller T, Sames-Dolzer E, Paulus P, et al. Long-term Evaluation of the Ross Procedure in Acute Infective Endocarditis. Semin Thorac Cardiovasc Surg 2017.

43. Ringle A, Richardson M, Juthier F, et al. Ross procedure is a safe treatment option for aortic valve endocarditis: Long-term follow- up of 42 patients. Int J Cardiol 2016;203:62-8.

44. Pettersson GB, Hussain ST, Ramankutty RM, Lytle BW, Blackstone EH. Reconstruction of fibrous skeleton: technique, pitfalls and results. Multimed Man Cardiothorac Surg 2014:2014.

45. Elgharably H, Hakim AH, Unai S, et al. The incorporated aortomitral homograft for double-valve endocarditis: the "hemi- Commando" procedure. Early and mid-term outcomes. Eur J Cardiothorac Surg 2018;53:1055-61.

46. Yankah AC, Pasic M, Klose H, Siniawski H, Weng Y, Hetzer R. Homograft reconstruction of the aortic root for endocarditis with periannular abscess: a 17-year study. Eur J Cardiothorac Surg 2005;28:69-75.

47. Leontyev S, Borger MA, Modi P, et al. Surgical management of aortic root abscess: A 13-year experience in 172 patients with $100 \%$ follow-up. J Thorac Cardiovasc Surg 2012;143:332-7.

48. Shrestha M, Khaladj N, Baraki H, et al. Aortic root reoperation: a technical challenge. J Heart Valve Dis 2010;19:177-81.

49. Jassar AS, Bavaria JE, Szeto WY, et al. Graft Selection for Aortic Root Replacement in Complex Active Endocarditis: Does It Matter? Ann Thorac Surg 2012;93:480-7.

Disclosure and conflicts of interest: The authors declare no conflict of interest.

Financial support: None. 